\title{
Ethanol prodution from mucilage and pulp of processed coffee
}

\section{Olivier Hirwa, Innocent Nyagahungu, Clement Bitwayiki}

\author{
University of Rwanda, College of Agriculture, Animal Sciences and Veterinary \\ Medicine, School of Food Science and Technology, Kigali, Rwanda
}

\section{Keywords: \\ Coffee pulp \\ Mucilage \\ Saccharomyces \\ cerevisiae \\ Ethanol \\ Fermentation}

\section{Article history:}

Received 04.06.2016

Received in revised form 15.08.2016

Accepted 01.09.2016

\section{Corresponding author:}

Clement Bitwayiki

E-mail:

blclement2@yahoo.com

\section{Abstract}

Introduction: The present investigation is to evaluate ethanol production from coffee pulp and mucilage as coffee by-products, which was used as substrate.

Material and methods: Wort extracted from pulp and mucilage was fermented; molasses sugar was used to optimize in terms of concentration and increase reducing sugars for fermentation process; acid hydrolysis was performed to breakdown complex polysaccharides from pulp and mucilage into simple monomers. Dry yeasts used as Saccharomyces cerevisiae were rehydrated and supplemented by nutrients rich in nitrogen, magnesium and carbon before being pitching in the wort; appropriate materials for hermetic process of fermentation were used and regular controlled.

Results and discussion: The variation of reducing sugars in a substance shows the evolution of fermentation process. During this fermentation process, it has been realized that the sugar content has decreased, by comparing with the initial level and final, before and after fermentation, is directly related to the fermentation efficiency. The end of process was realised when the density has decreased below $6 \%$. The obtain results after fermentation, was also continued by conducting distillation; the 6.51 as amount of wort produced 2.31 of ethanol with $45 \%$ absolutely volume, equivalent to $35.5 \%$ of wort volume. Since $\mathrm{pH}$ of wort was optimised to 4-5 for fermentation, the results show that ethanol production can be produced and viable using coffee pulp and mucilage as by-products and reduce the contamination of them to the environment. For this case study, by optimizing alcohol concentration, the $\mathrm{pH}$, and temperature have been kept constant for all samples.

Conclusion: Processing of the coffee mucilage and pulp as by-products to ethanol can increase raw material resources suitable for ethanol production for various purposes in Rwanda and this confirm that ethanol production from mucilage and pulp of coffee is possible as results show the potential to use them instead of considering them as waste. 


\section{Introduction}

Rwandan coffee has a balanced flavour, aroma and fruity taste which make it among the top rated coffee in USA, European and the Asian coffee markets. The main by-products from coffee processing are waste water, mucilage and pulp.

The by-products are rich in carbohydrates thus useful for various purposes including the potential for ethanol production. Types of coffee processing produce slightly different by-products.

Wet processing produces different by-products compared to dry method. In wet processing the coffee fruit is pressed in water through a screen which leaves a part of the pulp, the mucilage and the parchment still attached to the seeds (Belitz, et al. 2009).

The composition of Coffee pulp is ether extract: $(0.48 \%)$; crude fibre: $(21.4 \%)$; crude protein: (7.8\%); Pectic substances: $(6.5 \%)$; non-reducing sugar: $(2.0 \%)$; reducing sugar: (12.4\%); chlogenic acid: (2.6\%); caffeine: $(2.3 \%)$ and total caffeic acid: $(1.6 \%)$ (Gathuon, et al., 1991).

The coffee mucilage fraction remains adhered to the coffee bean in the wet processing which allows separation and concentration of the fraction. The composition of the mucilage is: water: $84.2 \%$; protein: $8.9 \%$; glucose (reducing): $2.5 \%$; sucrose (nonproducing): $1.6 \%$; pectin: $1.0 \%$ and ash: $0.7 \%$ (Clifford, Wilson, 1985 ).

This research studied ethanol production from a mixture of coffee by-products particularly pulp and mucilage of coffee. The Fermentation and distillation processes of the raw materials and evaluation of the main process variables of coffee processing as byproducts was conducted. Ethanol production as one of the applications of these wastes, as they contain carbohydrates which can be used for fermentation. The objective of the research:

- Minimize negative effects of coffee pulp and mucilage to the environment;

- Value addition to the coffee pulp and mucilage;

- Increase raw material resources suitable for ethanol production.

\section{Materials and methods}

\section{Source of samples}

The coffee by-products used in the study were of coffee Arabica variety from coffee station in the eastern province of Rwanda specifically $35 \mathrm{kgof}$ pulp and mucilage from one of the coffee washing stations in Rwamagana were used.

\section{Samples preparation}

Samples were prepared from pulp and mucilage based on different sugar contents. After the extraction of pulp and mucilage, samples of mixtures of all by-products were prepared, for each by-product different weight and Bx were used: $11 \mathrm{~kg}$ (sample A) with 10 degree $\mathrm{Bx} ; 8 \mathrm{~kg}$ (sample B) with 20 degree $\mathrm{Bx}$ and 2 samples of $6.5 \mathrm{~kg}$ with 15 degree $\mathrm{Bx}$ $(\mathrm{C}$ and $\mathrm{D})$. The other raw materials used were coffee water, water and molasses.

\section{Wort preparation}

The pulp with mucilage adhering on it, was passed through a mesh then through a manual extractor for juice extraction, care was taken not to cause physical damage to the structure. The juice obtained was collected in a well cleaned bucket in the laboratory. The juice was mixed with $10 \mathrm{~kg}$ of coffee waste water for wort preparation. 
All samples were sterilized by heating at $95^{\circ} \mathrm{C}$ for 900 seconds. Acid hydrolysis and regulation of fermentable sugars were simultaneously done to each sample. Yeasts were also prepared for each sample pulp by considering sample size obtained in extraction. It was necessary also to increase fermentable sugars by acid hydrolysis, where the hydrolysis of pectic substances in mucilage such as protopectin, increase the total sugar content (Fengel, 1979; Diana et al., 2011).

\section{Fermentation}

All samples were fermented separately, wort well aerated and cooled to $20-22{ }^{\circ} \mathrm{C}$ were subjected to fermentation. The $\mathrm{pH}$ of wort was optimised to 4-5 for fermentation. Yeast solutions were also prepared for each sample and were mixed with the corresponding samples to facilitate fermentation process. Air bubbles in the containers as well as the level of sugar content were monitored in the process and ethanol was progressively produced.

Ethanol (alcohol) measurement after fermentation this involves the measurement of the density of the wort before fermentation (FG). The ethanol concentration obtained was calculated by using Cyril JJ Berry formula:

$$
\% A B V=(O G-T G) / 0.736) \cdot 100
$$

where $\quad \mathrm{OG}-$ original specific gravity;

FG - final specific gravity;

7.36 - ethanol density.

\section{Distillation and identification}

Each sample was distilled separately and ethanol concentration was determined using an alcoholmeter, chemical reaction and combustions.

\section{Results and discussions}

\section{Handling of raw materials}

After reception of the raw materials, it was observed that their decomposition occurred immediately after processing. The decomposition was related to changes in soluble solids, $\mathrm{pH}$, color and odor over time, is associated with factors such as the quantity and quality of the water used in the processing of coffee, which was not of drinking quality.

\section{Fermentation process}

The process of fermentation was conducted and the obtained results are shown in the following Figure 1.

When the fermentation is going on, sugars are converted by yeasts to ethanol. The variation of reducing sugars in a substance shows the evolution of fermentation process. The fermentation is finished when the density has decreased by below $6 \%$.

Many times the fermentation stops before reaching that value, or can continue and goes below that value. It may be due to many factors related to $\mathrm{pH}$, sugar content, yeasts preparations etc. 


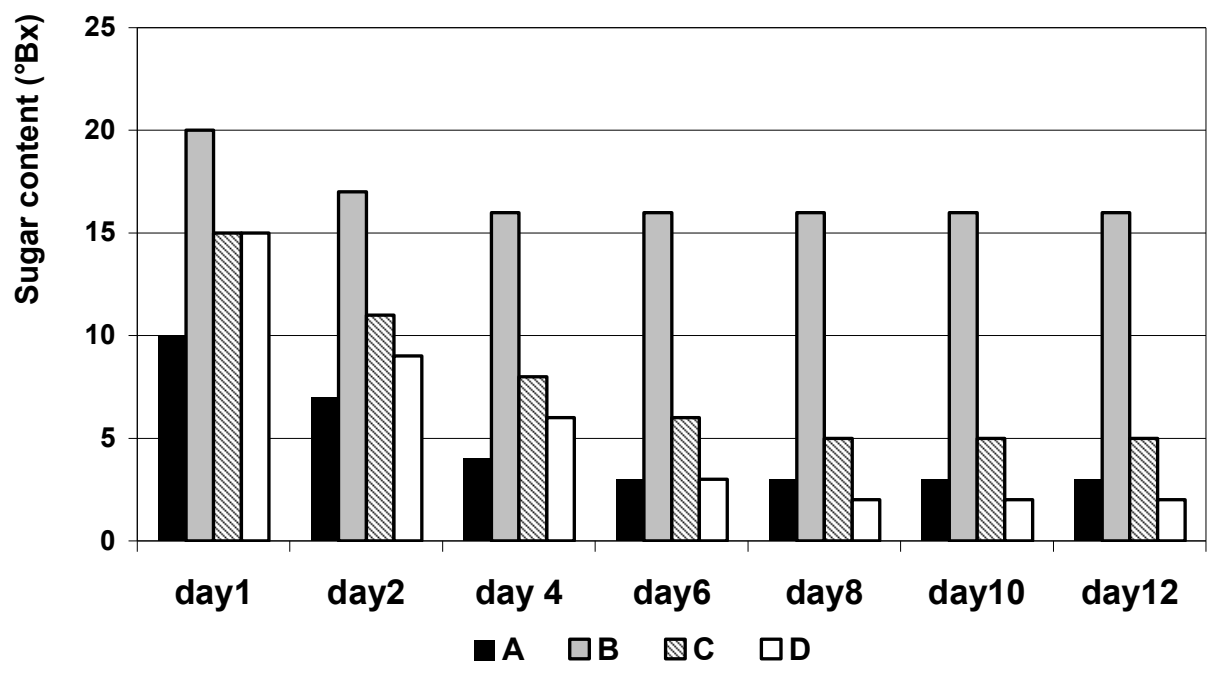

Figure 1. Variation in sugar content $\left({ }^{\circ} \mathrm{Bx}\right)$ over time, during fermentation in the sample A, B, C, D.

This results in very sweet or dry wines when they are for drinking, but for this case study, the non-well fermented wort will result in low yield of alcohol (i.e. ethanol concentration).

From Figure 1, it easy to see that sugar content varied differently over time, in the 4 samples:

- For Sample A, the Bx level decreased considerably from 10 to $2^{\circ} \mathrm{Bx}$;

- For Sample B, the Bx level decreased by only $3{ }^{\circ} \mathrm{Bx}$, it means from 20 to $17^{\circ} \mathrm{Bx}$;

- For Sample C, the Bx level decreased moderately from 15 to $5.5^{\circ} \mathrm{Bx}$;

- For Sample D, the Bx level decreased considerably from 15 to $2^{\circ} \mathrm{Bx}$.

The way sugar content have decreased during fermentation, by comparing the initial level before fermentation and the final level after fermentation is directly related to the fermentation efficiency.

For this case, for Sample D, where sugar content varied considerably from 15 to $2{ }^{\circ} \mathrm{Bx}$, it means that fermentation have been powerful, Although for Sample B, where sugar content decreased by only $3{ }^{\circ} \mathrm{Bx}$, from 20 to $17{ }^{\circ} \mathrm{Bx}$, it means that the fermentation have been inefficient.

When the fermentation has been inefficient, it means that sugars have not been converted into ethanol adequately, which means that the alcohol concentration in the fermented product should be low.

\section{Optimization of alcohol concentration}

From the following Figure 2, it is shown that the alcohol concentration varies for the 4 samples. It may due to the parameters which condition the fermentation process such as: yeasts preparation, temperature, $\mathrm{pH}$ adjustments, and sugar content.

For this case study, $\mathrm{pH}$, and the temperature have been kept constant for all samples, which means that the difference between the alcohol concentrations resides in 2 factors:

- Sugar concentration

-Yeasts preparation 


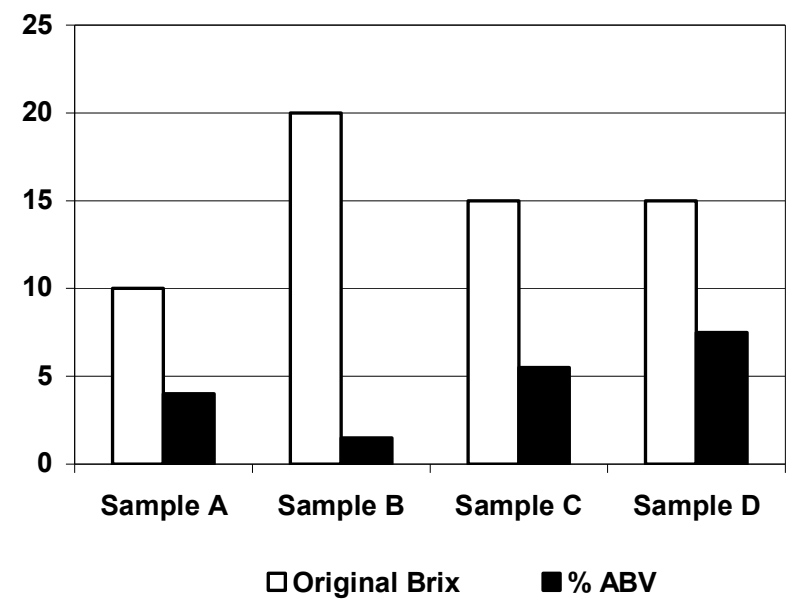

Figure 2. Comparison between the increase in Original Brix and\%ABV for all samples

\section{Optimization of alcohol quantity yield}

During fermentation, sugars are converted into alcohol, but all the sugars are not converted completely. After the fermentation; residues of sugar not fermented, dead yeasts, and other materials contained in wort which are not fermentable, sink in the bottom of fermenting vessel. Minimizing the available quantity of alcohol mixture in order to use it in the distillation process.

Alcohol quantity produced

Table 1

\begin{tabular}{|l|c|c|c|c|}
\cline { 2 - 5 } \multicolumn{1}{c|}{} & Sample A & Sample B & Sample C & Sample D \\
\hline Initial weight of wort ( kg) & $\mathbf{1 1}$ & $\mathbf{8}$ & $\mathbf{6 . 5}$ & $\mathbf{6 . 5}$ \\
\hline Weight of alcohol mixture $(\mathrm{kg})$ & $\mathbf{8}$ & - & $\mathbf{4 . 5}$ & $\mathbf{5 . 5}$ \\
\hline Percentage yield & $\mathbf{7 2 \%}$ & - & $\mathbf{6 9 \%}$ & $\mathbf{8 5 \%}$ \\
\hline Apparent attenuation (\%) & $\mathbf{8 0 \%}$ & $\mathbf{1 5 . 7 \%}$ & $\mathbf{6 3 \%}$ & $\mathbf{9 3 . 7 \%}$ \\
\hline
\end{tabular}

When sugars are not fermented sufficiently many sugar residues sink at the bottom, which results in a loss in the alcohol recuperation. By calculating the apparent attenuation, it was immediately anticipate the loss in alcohol recuperation as an increase in apparent attenuation corresponds to the increase in quantity available for distillation.

Thus, in order to increase the quantity of fermented substance which is available or usable in distillation, (which influences also the final ethanol concentration obtained after distillation), is to make sure that is done in the way of controlling all factors (Yeasts preparation, Optimum $\mathrm{pH}$, temperature, Not high level of sugars etc... as cited above).

As it is shown on Figure3, the Sample D has produced a high quantity of alcohol, both in the quantity and in concentration, as shown by Figure 2. On the other hand, the Sample $\mathrm{B}$, has not produced any valuable quantity for use, because its fermentation got stuck as shown, in figure 1. 


\section{— Food Technologies ——}

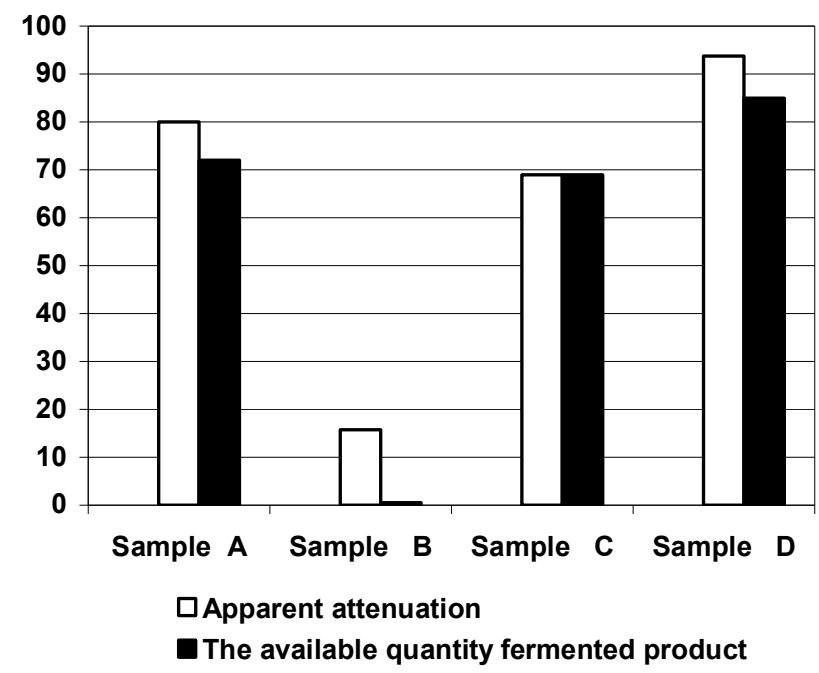

Figure 3. Relation between apparent attenuation increase and the increase of available quantity fermented product

\section{Quantity analysis of ethanol yield production}

During the distillation process all wine, beer, or fermented product content are not evaporated, because they are not ethanol or water. Thus, there will be some liquid which remains in distilling flask. These substances have been weighed and compared to the weight of the ethanol produced.

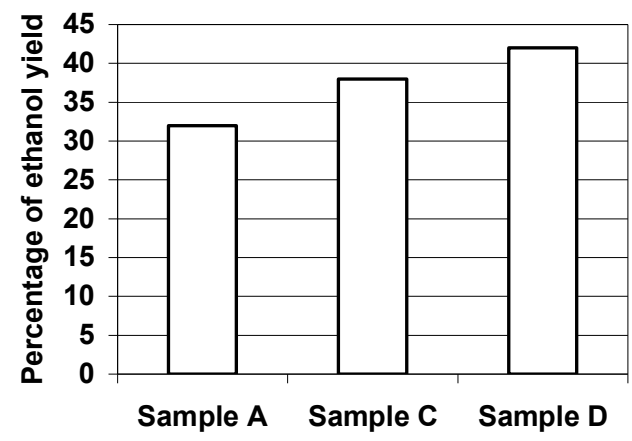

Figure 4. Ethanol yield percentage

The figure 4 shows that the production of ethanol in samples A, C and D was good and the best production of ethanol was high in the sample D compare to others. 


\section{Conclusions}

- Further studies on this topic can be conducted for moderation since it is a complex process and it necessitates more time and powerful equipment to explore each opportunity by analyzing deeply all details;

- The application of this project can help various institutions in Rwanda, dealing with environment, to reduce the environment threat caused by coffee processing by-products, and produce a valuable substance such as ethanol, which can be even used to produce energy.

\section{References}

1. Avallone S., Guiraud J.-P., Guyot B., Olguin E., Brillouet J.-M. (2000), Polysaccharide constituents of coffee-bean mucilage, Journal of Food Science, 65, pp. 1308-1311.

2. Belitz H.-D., Grosch W., Schieberle, P. (2009), Food chemistry (4th ed.), Heidelberg, Springer, (Chapter 21).

3. Bertrand B., Guyot B., Anthony F., Lashermes P. (2003), Impact of the Coffea canephora gene introgression on beverage quality of $\mathrm{C}$. arabica, Theoretical and Applied Genetics, 107.

4. Brand, D., Pandey, A., Roussos, S., \& Soccol, C. R. (2000), Biological detoxification of coffee husk by filamentous fungi using a solid state fermentation system, Enzyme Microb. Technol.

5. Bressani, R. (1978), The by-products of coffee berries. In J. E. Braham, \& R. Bressani (Eds.), Coffee pulp - composition, technology, and utilization, INCAP, pp. 5-10.

6. C.J.J. Berry (1987), First Steps in Winemaking, eighth edition, Special Interest Model Books Ltd.

7. Clifford Wilson (1985), Coffee Botany, Biochemistry and Production of Beans and Beverage, Crom Helm, pp 234-243.

8. Diana P. Navia, Reinaldo de J., Velasco M, José L. Hoyos C. (2011), Production and evaluation of ethanol from coffee processing by-products, Colombia, Vitae, Revista De La Facultad De Química Farmacéutica.

9. Esquivel P., Jim'enez V.M. (2011), Functional properties of coffee and coffee byproducts, Food Research International.

10. Forbes Robert James (1948), A short history of the art of distillation.

11. Franca A. S., Oliveira L. S., Ferreira, M. E. (2009), Kinetics and equilibrium.

12. Mualla Balaban (2003), Hydrolysis of Polysaccharides with $77 \%$ Sulfuric Acid for quantitative Saccharification. Instabul, Turk J Agric, 27(2003), pp. 361-365.

13. Gathuo B., Rantala P., Maatta R. (1991), Coffee Industry Wastes, Water Science Technology, 24(1), pp. 53-60.

14. Gielissen, R., Graafland, J. (2009), Concepts of price fairness: empirical research into the Dutch coffee market, Business Ethics: A European Review, 18, pp. 165-178.

15. Jacques K., Lyons T., Kelsall D. (1999), The alcohol textbook, A reference for the beverage, fuel and industrial alcohol industries. 3 a ed., Nottingham University Press, Nottingham.

16. Lashermes P., Andrade A. C., Etienne, H. (2008), Genomics of coffee, one of the world's largest traded commodities. In P.H. Moore, \& R. Ming (Eds.), Genomic of tropical crop plants, Springer, New York, pp. 203-225. 
17. Legras JL, Merdinoglu D, Cornuet J-M, Karst F. (2007), Bread, beer and wine: Saccharomyces cerevisiae diversity reflects human history.

18. Mburu, J.K., Thuo, J.T., Marder R.C. (1994), The characterization of coffee waste water from coffee processing factories in Kenya. In: Kenya Coffee., 59(690), pp. 17571761.

19. McBryde C., Gardner J.M., de Barros Lopes M., Jiranek V. (2006), Generation of novel wine yeast strains by adaptive evolution, American Journal of Enology and Viniculture, 57.

20. Prata E.R.B.A., Oliveira L.S. (2007), Fresh coffee husks as potential sources of anthocyanins, LWT-Food Science and Technology, 40, pp. 1555-1560.

21. Robinson Jancis (2006), The Oxford Companion to Wine, 3rd edition, Oxford University Press.

22. Ruiz A. (1997), Fermentación alcohólica del mucílago del café con levaduras, Universidad Nacional de Colombia, Medellín.

23. Treagust J. (1994), Coffee Waste Water Treatment. B.Sc. (Hons.), Cranfield University, Cranfield.

24. Ulloa-Rojas J.B., Verreth J.A.J., Amato S., Huisman E. A. (2003), Biologicaltreatments affect the chemical composition of coffee pulp, Bioresource Technology, 89, 267-274.

25. Vincent J.-C. (1987), Green Coffee Processing.. In: Clarke, R.J. and R. Macrae, ed., Coffee. Volume 2: Technology, Elsevier Science Publishers, New York, pp. 19-32.

26. (2003), Ministry of agriculture, Agriculture crop production in Rwanda. Kigali. Retrieved 15 March, available at: http//:www.minagri.gov.rw

27. (2009), Venkatesan Srinivasan, Sridhar Ramasamy, Sivakumar Venkatachalam, Shanmugam Periyasamy, 2009, Production of Bio-ethanol from Sugar Molasses using Saccharomyces Cerevisiae, Modern applied science, Retrieved April 23, available at: http://www.ccsenet.org/journal.

28. Ralph E. Kunkee and Maynard A. Amerine (1968), Sugar and Alcohol Stabilization of Yeast in Sweet Wine, Appl Microbiol., available at: http://www.books.google.com/books.

29. (2010), Sigrid Gertsen-Briand, Preventing and Fixing a Stuck Fermentation. Lallemand, Scott Labs., Retrieved, available at: http//:www.lallemandwine.us

30. Tata McGraw-Hill (2007), Textbook Of Food \& Beverage Mgmt, p. 268, available at: http://www.books.google.com/books. 